Proceedings

\title{
Harnessing the Energy of Tidal Currents: State-of- the-Art and Proposal of Use in EV Charging Points ${ }^{+}$
}

\author{
Aitor Fernández-Jiménez *, Daniel Fernández-de la Cruz, Jesús Ruiz-Torres, \\ Jose Luis Perrino-Blanco and Raúl Jimeno-Almeida \\ Hydraulic Engineering Area, Polytechnic School of Mieres, Gonzalo Gutiérrez Quirós Street, 33600 Mieres, \\ Spain; UO221562@uniovi.es (D.F-d-C.); UO260450@uniovi.es (J.R-T.); UO260486@uniovi.es (JL.P-B.); \\ UO259828@uniovi.es (R.J-A.) \\ * Correspondence: UO216958@uniovi.es \\ + Presented at the 2nd International Research Conference on Sustainable Energy, Engineering, Materials and \\ Environment (IRCSEEME), Mieres, Spain, 25-27 July 2018.
}

Published: 13 November 2018

\begin{abstract}
The implantation of floating platforms for the generation of electricity from tidal currents is possible due to the development of new hydrokinetic microturbines. This article presents an analysis of the situation in which the exploitation of tidal currents is nowadays, the state of art of the existing technologies and the principal projects that are currently underway. In addition, it focuses on the different aspects and criteria to consider for building one of these plants. Finally, an installation by floating platform is proposed to supply electricity to a charging station for electric vehicles near the Nalon river (Spain) with a description of it and an analysis of feasibility.
\end{abstract}

Keywords: tidal energy; floating-platform; charging-point

\section{Introduction}

The continuous researching of new energy sources has made possible the development of systems that can obtain energy from tidal currents. The worldwide theoretical potential is of 800 TWh/year [1] while in Europe is estimated in 40-50 TWh/year [2], This great energy potential available gives raise to the development of new designs that allows the use of this resource. In this way, the future growing demands of energy could be met. Figure 1 shows the evolution of electricity production by different energy sources in Spain since 2005.

New policies in the protection of the environment and the clean energy generation have encouraged the research of new technologies to harness the energy from tides. The liquid particles that make up the oceans are set continuously in motion by the action of the Sun and the Moon, describing closed orbits in different planes. So that, tidal currents are a renewable resource with high predictability. Tides can be harnessed by two ways: taking advantage of the difference of height between tides in tidal dams (tidal range energy) or using the water currents that are generated by tides on shore using hydrokinetic turbines (tidal current energy). However, the hydrokinetic use of tidal currents is a recent technology.

The main advantages of using hydrokinetic turbines for tidal currents are: it is a silent technology so it doesn't generate acoustic problems for the nearby population, has a theoretical continuous operation against other technologies that have much more variability, requires a lower initial investment because of their smaller size and produces less impact on the environment. 


\section{Evolution of electricity production by energy sources in Spain}

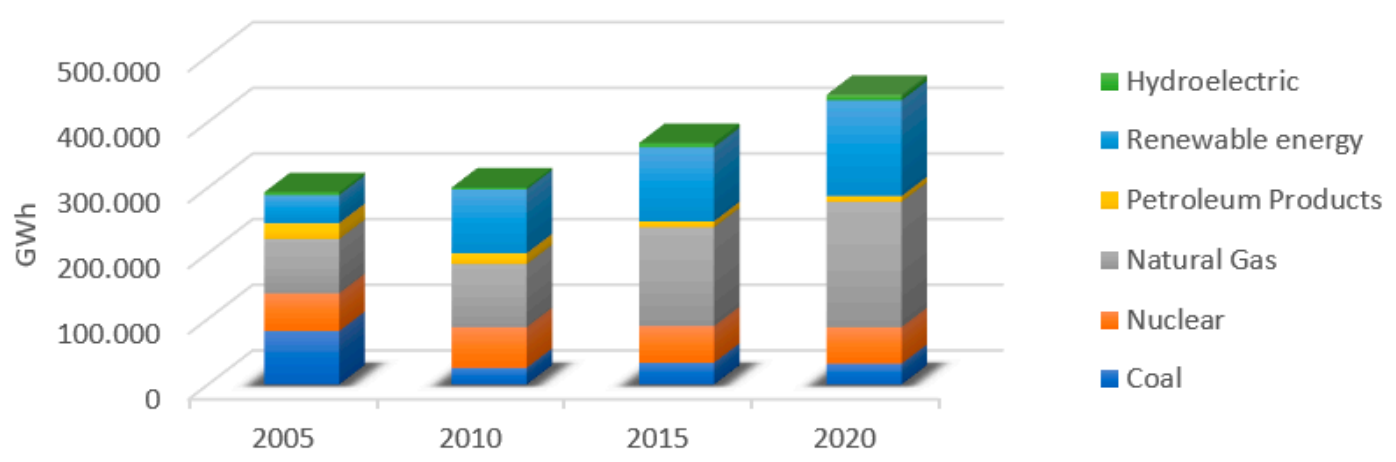

Figure 1. Evolution of electricity production by energy sources in Spain.

This article makes a review of the state-of-the-art technology related to the use of tides as an energetic resource, focusing on the use of hydrokinetic turbines. Accordingly, the different existing technologies and their use will be described. Also, the diverse aspects and criteria considered in the installation of a harnessing plant will be cited.

Finally, an installation by floating platform is proposed to supply energy to a charging station for electric vehicles (EV). This plant will be situated in the estuary of Nalon river (Asturias, Spain), using Gorlov vertical-axis microturbines to obtain energy from the tidal current speed. This type of turbines has been selected because of the small depth of the river and the easy installation of the device.

\section{Technologies}

Tidal range energy is based on the use of the potential energy produced by different levels, just like energy is obtained in reservoirs. Tidal current energy uses hydrokinetic vertical or horizontal turbines that rotate because of the kinetic term of the water currents.

The most important range energy plant is La Rance in France. It was built in 1966 on the estuary of Ille et Rance river with a total power installed of $240 \mathrm{MW}$. It took 20 years to amortize its construction cost. The main problem of tidal dams is the great environmental impact and the high initial investment required.

Hydrokinetic microturbines are based on the use of "cross-flow" turbines that rotate when the current impact the blades. Then the generator transforms the mechanic energy into electric energy while an electronic power system rectifies the electrical signal and makes it suitable for its connection to network. It is a new researching line and stills under investigation.

There have been numerous companies and technology centres that have been working on the improvement of devices that make their commercial use plausible. The first developed models used the Horizontal Axis Water Turbine (HAWT), which are analogous to wind rotors. An example is the Kepler Energy System [3] of $60 \mathrm{~m}$ of length and installed at a depth of $20 \mathrm{~m}$ in Bristol (United Kingdom). Unfortunately, these systems are very expensive because of its big dimensions and the necessity of being anchored at great depths.

To reduce costs, Vertical Axis Water Turbines (VAWT) have been developed. Most of them are based on an Darrieus turbine because are easily coupled to a floating platform and have a compact size. Although they have a lower installed power, the smaller initial investment and maintenance cost required compensates it use.

Related to VAWT, in 2008, a hydrokinetic turbine farm was built in Northern Ireland. The project was called Marine Current Turbine (MCT). It has a power installed of $1 \mathrm{MW}$ and is one of the biggest plants of this type in the world [4]. Other designs have been developed recently focused on the use of tidal currents but all of them are under researching programs. 


\section{Installation Aspects}

The main aspect for the installation of VAWT is the speed of the tidal current. In some parts of the English Channel or the Baltic sea, tidal currents can reach velocities of more than $1 \mathrm{~m} / \mathrm{s}$ [5]. Using the Equation (1), an energy of $0.92 \mathrm{MWh} /$ year can be obtained for a turbine of an area of $1 \mathrm{~m}^{2}$ for a current speed of $1 \mathrm{~m} / \mathrm{s}$ and a capacity factor of $70 \%$.

$$
E_{g}=0.5 \rho A v^{3} \cdot F_{\text {capacity }} \cdot 8760 \cdot C p
$$

where $E_{g}$ is the generated energy, $\rho$ is the seawater density $\left(1025 \mathrm{~kg} / \mathrm{m}^{3}\right), A$ is the area swept by the blades, $v$ is the velocity of the tidal current, $F_{\text {capacity }}$ is the capacity factor, 8760 are the hours that has a year and $C p$ is the performance of a Gorlov turbine that is approximately of $30 \%$.

Another important aspect is relative to the environmental impact. Also, VAWT greatly reduces the landscape impact due to its small size and the development of "open-rotor" designs reduce the mortality of fish species [6].

The legal aspects that regulates the installation of these systems is also important. These laws are focused on the regulation of the environmental affections and on the generation process. The European Ocean Energy Agency (EOEA) committed in 2013 to develop a common legal framework that regulates the installation and exploitation of maritime energy, encouraging through calls for the installation of tidal power plants. It is estimated that this technology can create more than 20,000 direct jobs before 2013 and move around 5300 million dollars by 2050 [7].

Finally, the price of these plants is obtained considering the price of electricity in the country where the turbines are settled, the installation and the maintenance costs and the fiscal regime. It is estimated that the price per $\mathrm{kW}$ of this type of harnessing plants is $1500 € / \mathrm{kW}$ [8].

\section{Researching Lines}

The European Union (EU) and other countries such as Canada or China are the main nations in the development and implementation of marine exploitation systems. One of the most important centers is the European Centre for Marine Energy (EMEC). It was built in 2003 in United Kingdom, focused on the development of tidal energy systems. In Canada, the Fundy Ocean Research Centre (FORCE) is world leader in the study of "in-stream tidal energy".

In recent years, the EU has implemented financing projects and the access to technology centers such as EMEC or IH Institute in Santander (Spain). The most important calls are the FORESEA (2016) and MaRINET (2017), that are published annually. In both projects, numerous universities, technological institutes and companies with big experience in renewable energies participate.

\section{Installation Proposal}

The construction of a floating-platform formed by 9 "open-rotor" VAWT is proposed for supply energy to a EV charging point. It will be located in the estuary of Nalon river (Asturias, Spain), where speeds of $2 \mathrm{~m} / \mathrm{s}$ are reached (potential of $4 \mathrm{~W} / \mathrm{m}^{2}$ ) [9]. Table 1 shows the main dimensions of the system.

Table 1. Main dimensions of the platform.

\begin{tabular}{cccc}
\hline \multicolumn{2}{c}{ Turbine } & \multicolumn{2}{c}{ Structure } \\
\hline Height & $1 \mathrm{~m}$ & Length & $12.30 \mathrm{~m}$ \\
Diameter & $1 \mathrm{~m}$ & Length with piles & $15.10 \mathrm{~m}$ \\
No blades & 3 (NACA 012) & Height & $0.40 \mathrm{~m}$ \\
Height with generator & $1.81 \mathrm{~m}$ & Freeboard & $1 \mathrm{~m}$ \\
\hline
\end{tabular}

Generators will be placed superficially on the platform, being connected by wires to the power control unit settled in the river's shore avoiding moisture problems. Figure 2 illustrates the floating platform design. To avoid the possibility of the platform leaving the selected location, four piles have been anchored to the river bed. 


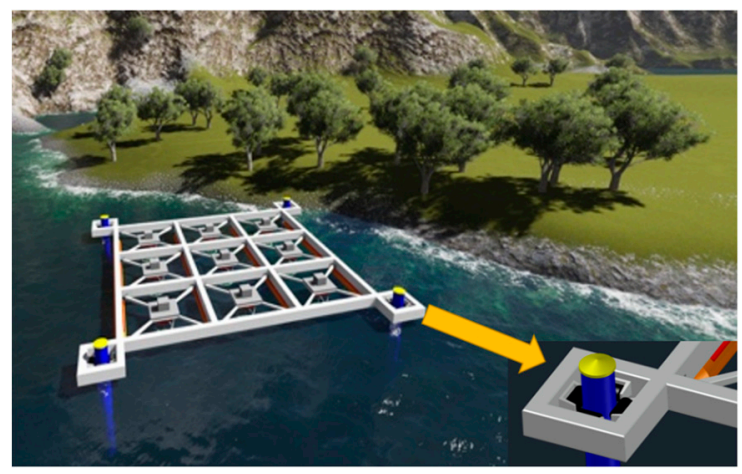

Figure 2. Platform design.

The theoretical installed power of the installation is of $10.8 \mathrm{~kW}$, which represents an annual energy generation of $66 \mathrm{MWh} /$ year. With this energy generated and assuming a standard $60 \mathrm{kWh}$ electric vehicle battery [10], a car would be able to travel up to $440.000 \mathrm{~km}$. Thus, 0.6 tons of $\mathrm{CO}_{2}$ wouldn't be emitted to the atmosphere, which represents a significant reduction of emissions to the atmosphere.

The initial investment required is of 58,310.42€, considering the construction and elements costs. A feasibility study was carried out using two different parameters: Internal Rate Return (IRR) and Pay Back (PB). Values of 2.34\% of IRR and 13, 18 years of PB have been obtained.

\section{Conclusions}

The utilization of tidal currents for power generation is possible due to the development of new compact designs of hydrokinetic microturbines. These turbines can be assembled to floating platforms situated near the coast, minimizing both environmental impact and electrical connection.

In this work, the different components have been described indicating the dimensions and number of elements required. Finally, a feasibility study has been carried out, obtaining good indicators to undertake the in the investment. Future research will seek to increase the installed power and the search of new uses where the platform can supply energy.

\section{References}

1. IEA. Key World Energy Statistics; IEA: Paris, France, 2017.

2. Lalander, E.; Grabbe, M.; Leijon, M. On the velocity distribution of hydrokinetic energy conversion from tidal currents and rivers. J. Renew. Sustain. Energy 2013, 5, 023115, doi:10.1063/1.4795398.

3. Wu, H.-N.; Chen, L.-J.; Yu, M.-H.; Li, W.-Y.; Chen, B.-F. On design and performance prediction of the horizontal axis water turbine. Ocean Eng. 2012, 50, 23-30, doi:10.1016/j.oceaneng.

4. Soerensen, H.; Weinstein, A. Ocean energy: Position paper for IPCC. In Proceedings of the Scoping Conference on Renewable Energy, Lübeck, Germany, 20-25 January 2008.

5. Blanchard, J.; Chetouane, F. Simulation-based evaluation of tidal current power output characteristics. Int. J. Renew. Energy Technol. 2010, 1, 408-423.

6. Marine and Hydrokinetic Environmental Policy Workshop; NYSERDA: New York, NY, USA; 2012.

7. Pathway to Commercialization; European Marine Energy Centre (EMEC): Orkney Islands, UK, 2016.

8. Álvarez, E.; Navarro, A.; Gutiérrez, A.; Fernández, J.; Rico, M. Design and feasibility study of a microgeneration system to obtain renewable energy from tidal currents. J. Renew. Sustain. Energy 2014, 6, 033109, doi:10.1063/1.4878845.

9. Fernández, D.; Álvarez, E.; Gutiérrez, A. Evaluación del potencial energético de las Corrientes de marea en la desembocadura del río Nalón (Asturias, España) mediante simulación de flujo unidimensional. Ing. del Agua (JIA) 2015, 19, doi:10.4995/ia.2015.3260.

10. Peña, C. Estudio de Baterías Para Vehículos Eléctricos; Universidad Carlos III de Madrid: Madrid. Spain; 2014. 